\title{
Nuclear and mitochondrial genetics in Parkinson's disease
}

\author{
A H V Schapira
}

Parkinson's disease (PD) is characterised clinically by bradykinesia, rigidity, and tremor. Onset is gradual and, in retrospect, symptoms may have been present for several years before medical attention was sought. The pathological correlate of the major clinical and pharmacological features of PD is the death of dopaminergic neurones in the zona compacta of the substantia nigra. At the time of presentation it is estimated that striatal dopamine levels have fallen by $80 \%^{1}$; by extrapolation, therefore, neuronal cell loss is already well advanced when diagnosis is made.

PD is seen all over the world but its prevalence in the developed countries is probably greater than elsewhere. In the west, prevalence is estimated at $150 / 100000$ with an annual incidence of 15-20/100 000 and a lifetime risk of development of 1 in 40 .

The cause of PD is unknown. A genetic component has been considered for many years but, with the exception of occasional families with atypical PD (parkinsonism), no clear link has emerged. The discovery of mitochondrial NADH CoQ ${ }_{1}$ reductase (complex I) deficiency in PD substantia nigra has raised the possibility that mitochondrial DNA may be involved. This article seeks to review critically the evidence for a genetic component to PD and then attempts to provide a simple working model for aetiology.

\section{Twin studies}

The first twin study was published in 1981 and found no concordance among 12 monozygotic twin pairs. ${ }^{2}$ The same group expanded their series of twins to 43 monozygotic and $19 \mathrm{di}-$ zygotic pairs, one of each twin pair having definite PD. ${ }^{3}$ Again, there was no increase in frequency among the identical twins. A similar analysis of 18 monozygotic and 14 dizygotic twins in Finland failed to identify any increased concordance for PD. ${ }^{4}$ A survey of 22 twins in the UK showed no aggregation of $\mathrm{PD}$ among these pairs. ${ }^{5}$ Thus, at least by virtue of the results of these twin studies, there did not appear to be a significant heritable factor in PD. However, the twin studies have been reanalysed and it has been suggested that no clear conclusions can be drawn from them. ${ }^{6}$

The difficulties with twin studies include the ascertainment of the diagnosis in the affected twin, establishing whether the apparently nor- mal co-twin is affected or not, and interpreting the relevance of associated disorders. In PD, for instance, the error rate for clinical diagnosis is 15 to $20 \%$, even in experienced hands and with well defined criteria. ${ }^{7} \mathrm{PD}$ is thought to have a long latent period, probably of several years; thus a study without follow up may fail to identify co-twins who were previously recorded as being unaffected and subsequently developed PD. ${ }^{18} \mathrm{~F}$-dopa uptake into the striatum of PD patients as detected by positron emission tomography (PET) is reduced to a mean of $50 \%$ of control values. ${ }^{8}$ This technique has the capacity to detect significant decreases in ${ }^{18} \mathrm{~F}$-dopa uptake in apparently asymptomatic people exposed to 1-methyl-4-phenyl 1,2,3, 6 tetrahydropyridine (MPTP). ${ }^{9}$ In one study, mean ${ }^{18} \mathrm{~F}$-dopa uptake was significantly reduced $(14 \%)$ in some asymptomatic co-twins as well as in the affected twin $(62 \%) .{ }^{10}$ Four of the 10 monozygotic and two of the seven dizygotic asymptomatic co-twins in this report had significantly reduced ${ }^{18} \mathrm{~F}$-dopa uptake. Concordance values for nigrostriatal dysfunction in the monozygotic twins was $4.5 \%$ and $29 \%$ in the dizygotic twins at a 2 SD threshold, but were not statistically different. Interestingly three of the four asymptomatic monozygotic co-twins had postural or orthostatic tremor which raises the question of whether this is part of the clinical spectrum of PD.

In conclusion, twin studies have failed to provide clear guidance on the importance of a genetic component to PD. This results partly from the limitations of study design, as well as the probable heterogeneity of the disease.

\section{Family studies}

It was Gowers who first observed that patients with PD often had an affected relative and he suggested that hereditary factors might be important. ${ }^{11}$ Several kindreds with parkinsonism have been identified. Eight members of two generations in one family presented with clinical features typical of idiopathic PD with late onset, tremor, bradykinesia, and a good response to L-dopa. ${ }^{12}$ Two large kindreds (subsequently found to have a common ancestor) have been described with 41 affected members, characterised by young onset (mean age $46 \cdot 5$ ), bradykinesia, and response to L-dopa. ${ }^{13} \mathrm{Cer}-$ tain features in these families were unusual,

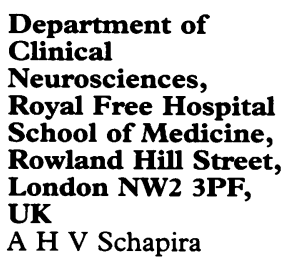


including lack of tremor and an aggressive course of disease. Two patients came to necropsy; one had morphological changes typical of PD, that is, nigral cell loss and nigral Lewy bodies; the other had cell loss and Lewy bodies in the locus ceruleus but the nigra was not available for study. These and other family studies suggest that $\mathrm{PD} /$ parkinsonism, when inherited, may be transmitted by an autosomal dominant gene with variable penetrance. ${ }^{14} \mathrm{An}$ ${ }^{18}$ F-dopa PET study of one kindred with PD showed decreased striatal uptake in affected as well as several clinically unaffected members in addition to one young member with a postural tremor. ${ }^{15}$ This suggests that studies where ascertainment of disease is limited to clinical examination will miss "at risk" or preclinical cases and, thus, as with the twin data, underestimate the gene penetrance.

\section{Clues to the pathogenesis of PD}

The discovery that MPTP is selectively neurotoxic to the dopaminergic neurones of the substantia nigra and can induce parkinsonism in man and other primates has provided many valuable insights into potential pathogenetic mechanisms in idiopathic PD. ${ }^{1617}$ MPTP causes cell death through a series of uptake and conversion steps which allow it to inhibit specifically complex I of the mitochondrial respiratory chain. ${ }^{18}$ The resulting fall in ATP synthesis is also probably associated with the generation of free radicals. It is interesting that there appear to be several important parallels at the biochemical level between the effects of MPTP and changes in the substantia nigra in PD patients. There is evidence for specific deficiency of complex I activity in PD substantia nigra ${ }^{19}$ and this appears anatomically selective for the nigra within the central nervous system and disease specific for $\mathrm{PD} .{ }^{20} \mathrm{In}$ addition there are also changes indicating oxidative stress and damage in PD nigra, ${ }^{21}$ probably accelerated by the presence of increased iron without a concomitant rise in ferritin levels. ${ }^{22}$

The changes of mitochondrial dysfunction and oxidative damage might represent either the terminal events of a cascade of reactions originating in a quite different biochemical event, or constitute primary phenomena which are genetically or environmentally induced and which themselves directly cause nigral cell death. Genetic defects resulting in complex I deficiency ${ }^{23}$ or altered free radical metabolism ${ }^{24}$ may each be associated with human disease. Attention has therefore focused on the possibility that mutations in genes encoding complex I subunits or the enzymes of free radical metabolism may be involved in PD. This may be either through a direct effect or indirectly through an interaction with an environmental agent. The latter possibility has led to the concept of susceptibility genes for PD.

\section{Linkage studies and susceptibility genes in PD}

Linkage studies on families with autosomal dominantly inherited parkinsonism have failed to identify any candidate genes. However, several putative genes have been excluded, including glutathione peroxidase, tyrosine hydroxylase, brain derived neurotrophic factor, catalase, amyloid precursor protein, $\mathrm{CuZn}$ superoxide dismutase, and debrisoquine 4-hydroxylase (CYP2D6B). ${ }^{25}$

The evidence for abnormal xenobiotic metabolism in $\mathrm{PD}^{26}$ together with some evidence for altered debrisoquine metabolism ${ }^{27}$ led to the search for an association between certain cytochrome $\mathrm{P} 450$ gene alleles and sporadic PD. Several groups have now shown an increased incidence (risk ratio approximately $2: 5$ ) of the CYP2D6B allele among patients with PD. ${ }^{28-30}$ The CYP2D6B allele was not found in increased frequency in Alzheimer's disease (AD) or its Lewy body variant. ${ }^{30} \mathrm{~A}$ monoamine oxidase $B$ allele has been associated with a relative risk for PD of $2 \cdot 0,{ }^{31}$ although this has not been confirmed by another study. ${ }^{32}$ The $\varepsilon 4$ isoform of apolipoprotein $\mathrm{E}$ is recognised as a risk factor for familial and sporadic $\mathrm{AD} .{ }^{33}$ The question as to whether the $\varepsilon 4$ allele may be related to PD dementia is uncertain; one study found no association ${ }^{34}$ while another discovered an increased frequency of the allele in demented PD patients. ${ }^{35}$

\section{Mitochondrial inheritance}

The mitochondrial genome is a circular double stranded molecule of 16.5 kilobases $(\mathrm{kb})$ and encodes 22 transfer RNAs, two ribosomal RNAs, and 13 polypeptides, all of which are part of the respiratory chain.

Mutations of mitochondrial DNA (mtDNA) have now been associated with numerous human diseases: deletions and duplications with ophthalmoplegia; tRNA mutations with encephalomyopathies, diabetes mellitus, and cardiomyopathy; and polypeptide coding gene mutations with Leber's hereditary optic neuropathy (LHON). ${ }^{36}$ The relationship between genotype and clinical or biochemical phenotype in these disorders is complex and far from understood. MtDNA mutations usually exhibit heteroplasmy, the coexistence of mutant and wild type molecules in the same tissue and possibly in the same mitochondrion. The proportion of mutant molecules may vary as may the threshold for biochemical expression between mutations: $>60 \%$ for deletions ${ }^{37}$ and $>95 \%$ for tRNA mutations. ${ }^{38}$ The dependency of a tissue on oxidative phosphorylation for energy provision may also determine its response to a given mutant load. In this respect, brain and muscle may be more sensitive to a defect than other tissues. MtDNA is highly polymorphic and so there is a growing realisation that not all apparent "mutations" are pathogenic. Generally, the presence of heteroplasmy, an important base and amino acid change in a significantly conserved region, and the absence of the same sequence change in controls, will substantially increase the chances of pathogenicity.

MtDNA encodes seven of the 41 subunits of complex I and so mutations of this genome could contribute to or cause the complex I 
defect in PD substantia nigra. Although there is no direct evidence for mitochondrial inheritance in PD families, this does not exclude a mitochondrial component to the expression of the disease. The apparently inconclusive results of the twin studies could be the result of a compounding effect of maternal inheritance. Examples of such bigenomic effects are now beginning to emerge. LHON is a disorder associated with specific point mutations in mtDNA complex I genes. However, 80 to $85 \%$ of sufferers are male, implying some linkage to the $\mathrm{X}$ chromosome. Similarly a mtDNA ribosomal RNA mutation has been identified in an Arab-Israeli family with maternally inherited deafness in which an autosomal recessive gene is also thought to play a role. ${ }^{39}$

The search for specific mtDNA mutations in PD has, to date, proved unrewarding. ${ }^{4041}$ The $4.9 \mathrm{~kb}$ "common" deletion was thought to accumulate in increased amount in PD striatum, ${ }^{42}$ but this was subsequently shown merely to be an aging phenomenon. ${ }^{434}$ Although the common deletion does accumulate with advancing years in brain, liver, and muscle, its absolute proportion is estimated at 0.01 to $0 \cdot 1 \%$ of all mtDNA. ${ }^{45}$ Thus this mutation alone will not account for the complex I defect observed in PD.

Several groups have sought to identify specific mtDNA mutations in PD or $\mathrm{AD}$ or both. One report has suggested that mitochondrial encephalopathies and PD are members of the same gene family. ${ }^{46}$ The complex I ND-1 gene has been sequenced in the blood of $26 \mathrm{PD}$ patients but no significant mutations were found. ${ }^{47}$ An extensive study for mtDNA polymorphisms was undertaken from $73 \mathrm{AD} / \mathrm{PD}$ brains, $62 \mathrm{AD}$ brains, and 32 blood and six muscle samples from PD patients. ${ }^{48}$ Four restriction site variants were identified, three of which were homoplasmic. A tRNA ${ }^{\text {Gln }}$ variant was present in two of $62 \mathrm{AD}$ brains, five of $73 \mathrm{AD} / \mathrm{PD}$ brains, two of $38 \mathrm{PD}$ patients, and 12 of 1691 ethnic controls. An ND1 variant was seen in two of $73 \mathrm{AD} / \mathrm{PD}$ brains but not in $62 \mathrm{AD}$ brains or $38 \mathrm{PD}$ samples, and was present in seven of 1051 controls. A $12 S$ variant was found in one of the $A D / P D$ patients with the tRNA ${ }^{\mathrm{Gln}}$ polymorphism but was also found in 699 controls. Finally, a heteroplasmic 16S variant was found in several brain regions of one $\mathrm{AD}$ patient at approximately $50 \%$ of the mtDNA population. Two of 699 controls were homoplasmic for the same variant. These mtDNA variants occur in low frequency among PD patients and cannot at present be considered pathogenic. Another group has studied 20 PD blood samples and did not find any patient positive for the tRNA ${ }^{\text {Gln }}$ mutation (D Krige, personal communication). However, the idea of certain mtDNA "polymorphisms" increasing the risk of a person developing PD is an attractive one, if still at present entirely hypothetical. Aminoglycoside induced deafness is an intriguing example of how such polymorphisms may generate susceptibility, in this case to an environmental agent. Aminoclygoside antibiotics target bacterial ribosomal RNA and so the $12 \mathrm{~S}$ and $16 \mathrm{~S}$ mtDNA genes were examined in Chinese in whom there was evidence of a maternally inherited susceptibility to aminoglycoside induced deafness. A homoplasmic variant at nucleotide 1555 in the $12 \mathrm{~S}$ RNA was identified in affected subjects but not in 278 ethnic controls. This change was thought to alter the conformation of the ribosomal RNA so as to increase aminoglycoside binding.

The tissue distribution of the complex I defect in PD might provide some clues as to its pathogenic relevance and the potential role of mtDNA in its aetiology. Extensive analyses of numerous regions of PD brain have shown that the complex I deficiency is highly selective for the substantia nigra and is not present in caudate, putamen, tegmentum, globus pallidum, cerebral cortex, cerebellum, or substantia innominata. ${ }^{204950}$ The uniformity of results in CNS studies is not mirrored in the analyses of skeletal muscle or blood from PD patients. ${ }^{51}$ Several groups have now published their data on mitochondrial function in these tissues. An appraisal of these shows that in the majority of PD patients, skeletal muscle is morphologically and biochemically normal in terms of mitochondrial function whereas there appears to be a limited but consistent decrease of complex I activity in platelets. However, it may be misleading to reduce a potentially aetiologically heterogeneous disease such as PD to crude group to group analysis with controls. It may be, for instance, that a small proportion of PD patients have a systemically distributed mtDNA mutation that may either induce a widespread respiratory chain defect or mild deficiency which is amplified by the local biochemistry, for example, the oxidative stress of the substantia nigra.

There have been several important advances in the past five years in our understanding of the potential causes of PD. To date, these have served to confound some previously held simplistic beliefs and have engendered the view that the aetiology of PD is multifactorial in the majority of patients. The concept of genetic susceptibility to an environmental agent ${ }^{39}$ has already reaped rewards in identifying at least one susceptibility gene (CYP2D6B), although its influence must still be regarded as weak. Experience with $\mathrm{AD}$ and motor neurone disease would suggest that any gene responsible for familial PD may not be found either in all families or in sporadic cases. The case for mtDNA mutations playing a role in $P D$ is still unresolved but the data for mitochondrial dysfunction in PD make further examination of this genome an exciting prospect.

1 Bernheimer H, Birkmayer W, Hornykiewicz OO, et al. Brain dopamine and the syndromes of Parkinson and Hundopamine and the syndromes of Park
tington. $₹$ Neurol Sci 1973;20:415-55.

2 Duvoisin RC, Eldridge R, Williams A, Calne D. Twin study of Parkinson disease. Neurology 1981;31:77-80.

3 Ward CD, Duvoisin RC, Ince SE, et al. Parkinson's disease in 65 pairs of twins and in a set of quadruplets. Neurlogy 1983;33:815-24

4 Martilla RJ, Kaprio J, Koskenvuo MD, Rinne UK. Parkinson's disease in a nationwide twin cohort. Neurology 1988;38:1217-9.

5 Marsden CD. Parkinson's disease in twins. $f$ Neurol Neurosurg Psychiatry 1987;50:105-6.

6 Johnson WG, Hodge SE, Duvoisin R. Twin studies and the genetics of Parkinson's disease - a reappraisal. Movement Disord 1990;5:187-94.

7 Hughes AJ, Ben-Shlomo Y, Daniel SE, Lees AJ. What 
features improve the accuracy of clinical diagnosis in Parkinson's disease: a clinicopathologic study. Neurology 1992;42:1142-6.

8 Brooks DJ, Ibanez V, Sawle GV, et al. Differing patterns of structural ${ }^{18} \mathrm{~F}$-dopa uptake in Parkinson's disease, multiple system atrophy and progressive supranuclear palsy. Ann

9 Calne DB, Langston JW, Martin WR, et al. Positron emission tomography after MRI: observations relating to the cause of Parkinson's disease. Nature 1985;317:246-8.

10 Burn DJ, Mark MH, Playford ED, et al. Parkinson's disease in twins studied with ${ }^{18} \mathrm{~F}$-dopa positron emission tomography. Neurology 1992;42:1894-900.

11 Gowers WR. A manual of diseases of the nervous system. 2nd ed. Philadelphia: Blakiston, 1903:636

12 Degl'Innocenti F, Maurello MT, Marini P. A parkinsonian kindred. Ital $\mathcal{F}$ Neurol Sci 1989;10:307-10.

13 Golbe LI, Di Iorio G, Bonavita V, Miller DC, Duvoisin RC. A large kindred with autosomal dominant Parkinson's disease. Ann Neurol 1990;27:276-82.

14 Lazzarini AM, Myers RH, Zimmerman TR, et al. A clinical genetic study of Parkinson's disease: evidence for domgenetic study of Parkinson's disease: evidence
inant transmission. Neumlogy 1994;44:499-506.

15 Sawle GV, Wroe SJ, Lees AJ, et al. The identification of presymptomatic parkinsonism: clinical and $\left[{ }^{18} \mathrm{~F}\right] \mathrm{dopa}$ positron emission tomography studies in an Irish kindred. Ann Neurol 1992;32:609-17.

16 Burns RS, Chiueh CC, Markey SP, et al. A primate model of Parkinsonism: selective destruction of dopaminergic neurons in the pars compacta of the substantia nigra by MPTP. Proc Natl Acad Sci USA 1983;80:4545-50.

17 Langston JW, Forno LS, Robert CS, Irwin I. MPTP causes selective damage to the zona compacta of the substantia nigra in the squirrel monkey. Brain Res 1984;292:390-4.

18 Tipton KF, Singer TP. Advances in our understanding of the mechanisms of the neurotoxicity of MPTP and related compounds. F Neurochem 1993;61:1191-206.

19 Schapira AHV, Cooper JM, Dexter D, et al. Mitochondrial complex I deficiency in Parkinson's disease. $¥$ Neurochem complex I deficien.

20 Schapira AHV, Mann VM, Cooper JM, et al. Anatomic and disease specificity of NADH CoQ 1 reductase (complex I) deficiency in Parkinson's disease. $\mathcal{F}$ Neurochem 1990;55 2142-5

21 Jenner P, Dexter DT, Sian J, et al. Oxidative stress as a cause of nigral cell death in Parkinson's disease and in cidental Lewy body disease. Ann Neurol 1992;32:S82-7.

22 Mann VM, Cooper JM, Daniel SE, et al. Complex I, iron and ferritin in Parkinson's disease substantia nigra. An Neurol 1994;36:876-81.

23 Schapira AHV, Cooper JM. Biochemical and molecular features of deficiencies of complexes I, II and III. In Schapira AHV, DiMauro S, eds. Mitochondrial disorders in neurology. Oxford: Butterworths Heinemann, 1994:75-90.

24 Rosen DR, Siddique T, Patterson D, et al. Mutations in Cu $\mathrm{Dn}$, Siddique T, Patterson D, et al. Mutations in (a) associated with familial amyotrophic lateral sclerosis. Nature 1993;362. $59-62$

25 Gasser T, Wszolek ZK, Trofatter J, et al. Genetic linkage studies in autosomal dominant parkinsonism: evaluation of seven candidate genes. Ann Neurol 1994;36:387-96.

26 Steventon GB, Heafield MTE, Waring RH, Williams AC. Xenobiotic metabolism in Parkinson's disease. Neurology 1989;39:883-7

27 Steiger MJ, Lledo P, Quinn NP, et al. Debrisoquine hy droxylation in Parkinson's disease. Acta Neurol Scand 1992; 86:159-64.

28 Armstrong $M$, Daly AK, Cholerton S, et al. Mutant debrisoquine hydroxylation genes in Parkinson's disease. Lancet 1992;339:1017-8

29 Smith CAD, Gough AC, Leigh PN, et al. Debrisoquine hydroxylase gene polymorphism and susceptibility to Parkinson's disease. Lancet 1992;339:1375-7.

30 Rempter R, Crook R, Houlden H, et al. Parkinson's disease, but not Alzheimer's disease, Lewy body variant associated with mutant alleles at cytochrome P450 gene. Lancet 1994

31 Kurth JH, Kurth MC, Poduslo SE, Schwankhaus JD. Association of a monoamine oxidase B allele with Parkinson's disease. Ann Neurol 1993;33:368-72.

32 Ho SL, Kapadi AL, Ramsden DB, Williams AC. Monoamine oxidase-B (MAO-B) polymorphism in Parkinson's disease. Movement Disord 1994;9(suppl):32.

33 Saunders AM, Strittmatter WJ, Schmechel D, et al. Association of apolipoprotein $\mathrm{E}$ allele $\mathrm{E} 4$ with late-onset familial and sporadic Alzheimer's disease. Neurology 1993; 43:1467-72.

34 Marder K, Maestre G, Cote L, et al. The apolipoprotein $\varepsilon 4$ allele in Parkinson's disease with and without dementia. Neurology 1994;44:1330-1.

35 Arai H, Muramatsu T, Higuchi S, et al. Apolipoprotein E gene in Parkinson's disease with and without dementia. Lancet 1994;344:889.

36 Harding AE. Neurological disease and mitochondrial genes. Trends Neurol Sci 1991;14:132-8.

37 Hayashi J-I, Ohta S, Kikuchi A, et al. Introduction of diseaserelated mitochondrial DNA deletions into HeLa cells lacking mitochondrial DNA results in mitochondrial dysfunction. Proc Natl Acad Sci USA 1991;88:10614-8.

38 Chomyn A, Meola G, Bresolin N, et al. In vitro genetic transfer of protein synthesis and respiration defects to mitochondrial DNA-less cells with myopathy-patient mitochondria. Mol Cell Biol 1991;11:2236-40.

39 Prezant TR, Agapian JV, Bohlman C, et al. Mitochondrial ribosomal RNA mutation associated with both antibioticinduced and non-syndrome deafness. Nature Genet 1993; 4:289-94.

40. Schapira AHV, Holt IJ, Sweeney M, et al. Mitochondrial DNA analysis in Parkinson's disease. Movement Disord 1990;5:294-7.

41 Lestienne P, Nelson J, Riederer P, et al. Normal mitochondrial genome in brain from patients with Parkinson's disease and complex I defect. $\mathcal{F}$ Neurochem 1990;55:1810 12.

42 Ozawa $T$, Tanaka $M$, Ikebe $S$, et al. Quantitative determination of deleted mitochondrial DNA relative to normal DNA in parkinsonian striatum by a kinetic PCR analysis. Biochem Biophys Res Commun 1990;172:483-9.

43 Mann VM, Cooper IM, Schapira AHV. Quantitation of a mitochondrial DNA deletion in Parkinson's disease. FEBS Lett 1992;299:218-22.

44 Lestienne P, Riederer P, Jellinger K. Mitochondrial DNA in postmortem brain from patients with Parkinson's disease. $f$ Neurochem 1991;56:1819.

45 Schapira AHV, Cooper JM. Mitochondrial function in neurodegeneration and ageing. Mutat Res 1992;275:13343.

46 Ozawa $\mathrm{T}$, Tanaka $M$, Ino $\mathrm{H}$, et al. Distinct clustering of point mutations in mitochondrial DNA among patients with mitochondrial encephalomyopathies and with Parwith mitochondrial encephalomyopathies and with Parkinson's
938-46.

47 Johns DR, Neufeld MJ. Analysis of mitochondrial DNA ND-1 gene in Parkinson's disease. Movement Disord 1991; 6:271.

48 Shoffner JM, Brown MD, Torrino A, et al. Mitochondrial DNA variants observed in Alzheimer's disease and Parkinson's disease patients. Genomics 1993;17:171-84.

49 Mann VM, Cooper JM, Krige D, et al. Brain, skeletal muscle and platelet homogenate mitochondrial function in Parkinson's disease. Brain 1992;115:333-42.

50 Janetzky B, Hauck S, Youdim MBH, et al. Unaltered aconitase activity but decreased complex I activity in substantia nigra pars compacta of patients with Parkinson's disease. Neurosci Lett 1994;169:126-8.

51 Schapira AHV. Evidence for mitochondrial dysfunction in Parkinson's disease: a critical appraisal. Movement Disord 1994;9:125-38. 